\title{
La investigación nacional en educación 2007 - 2011. Balance y agenda
}

\section{National education research 2007 - 2011. Balance and agenda}

\author{
Jorge A. Rodríguez ${ }^{1 \mathrm{a}}$
}

${ }^{1}$ Universidad San Ignacio de Loyola, Lima, Perú.

\begin{abstract}
${ }^{a}$ Magister en Sociología con especialidad en investigación social y evaluación de proyectos sociales. Director del Centro de Investigación de la Universidad San Ignacio de Loyola.
\end{abstract}

Recibido: 20-05-13

Aprobado: $25-08-13$

\section{Correspondencia}

Email: jrodriguezs@usil.edu.pe

Notas

Este documento fue desarrollado en el marco del concurso anual de investigación 2011 del Consorcio de Investigación Económica y Social, financiado por IDRC - Canadá y la Fundación Manuel J. Bustamante. Agradezco el aporte institucional del Centro de Estudios y Promoción del Desarrollo - desco para la realización de este balance. También el valioso apoyo de Marie Le Baron en el registro de muchos de los estudios. 


\section{Resumen}

El informe ofrece una mirada de la investigación nacional en educación con dos propósitos: (i) hacer un balance de lo hecho (y lo no hecho) y, a partir de ello, (ii) definir una agenda de investigación para el período inmediatamente posterior 20122016. El balance identifica los temas abordados con mayor énfasis, las orientaciones metodológicas empleadas y los marcos institucionales en que se hizo investigación. Establece también los resultados alcanzados, las tendencias de esos resultados, los vacíos u omisiones y lo que queda por hacer. La agenda de investigación identifica rutas de trabajo sobre aquellos temas que fueron abordados parcialmente, los que no fueron abordados o temas emergentes. El informe se elaboró empleando como fuente principal los resultados de la investigación hecha, a través de los típicos informes de investigación que incluyen preguntas, propósitos definidos, modelos de análisis y datos consolidados que les dan sustento. También se incluyó ensayos analíticos sobre la investigación de campo, en un determinado tema e informes de consultoría cuando se estimó que emplearon diseños investigativos con criterios mínimos de rigurosidad. Todas las fuentes fueron contrastadas con entrevistas a investigadores y tomadores de decisiones. La versión previa del informe, a su vez, fue validada en un taller con académicos, investigadores y funcionarios del sector.

Palabras clave: Investigación educativa, rendimiento académico, formación docente, descentralización educativa.

\section{Summary}

The report offers a perspective of national research in education with two purposes: (i) to take stock of what has been done (and not done) and, based on this, (ii) to define a research agenda 2012-2016 period. The study identifies the topics addressed with greater emphasis, the methodological guidelines employed, and the institutional frameworks in which the research was carried out. It also establishes the results achieved, the trends of those results, the gaps or omissions and what remains to be done. The research agenda identifies routes of work on those issues that were partially addressed, emerging issues and issues that were not addressed at all. The report was prepared using the results of the investigation as their main source; that is, including questions, the purposes defined, models of analysis and consolidated data to support them. Also, the report includes analytical essays on field research and consulting reports when it was estimated that they used research designs along with minimum rigor criteria. All sources were contrasted with researcher and decision maker interviews. The report first version was validated in a workshop with scholars, researchers and officials.

Key words: Educational research, academic performance, teacher training, educational decentralization. 
Este informe ofrece una visión general de la educación en el Perú desde lo producido por la investigación en los últimos cuatro años. Mucho de lo hecho en el período 2004-2007 -reseñado en el balance anterior (Cuenca, 2008)sigue vigente, como veremos más adelante. Entre 2007 y 2011, una importante cantidad de estudios profundizó en las materias ya trabajadas durante los períodos anteriores, a la que se sumó un número aún mayor que abordó otros temas o utilizó novedosas perspectivas de análisis. En total, hemos registrado 52 estudios entre un universo bastante más vasto. La intención fue reunir reflexiones, acercamientos y propuestas que contribuyesen a enriquecer nuestro conocimiento sobre la educación y abrir mejores rutas de búsqueda.

Por supuesto, la cifra de investigaciones desarrolladas supera a las presentadas por este balance. No se da cuenta aquí de todo lo trabajado en el campo y es probable que no se mencionen todos los estudios. Por ello, iniciamos el balance reconociendo sus límites, que tienen que ver con los obstáculos para acceder a estudios no publicados o bien con decisiones sobre lo que "debe estar" o "no debe estar", que finalmente se expresan en cómo hemos pensado y organizado el informe.

Los textos considerados son de diferentes tipos. Por un lado, están los típicos informes de investigación que contienen preguntas, propósitos definidos, modelos de análisis y datos consolidados que dan sustento a resultados o propuestas. En este mismo rubro se ubican los ensayos que recuperan y se apoyan en los resultados de la investigación disponible, así como a los informes de consultoría, principalmente evaluaciones, que en algunos casos formulan preguntas de investigación y definen estrategias para darles respuesta con mayor o menor éxito. Estos son la enorme mayoría.

Por otro lado, están los textos que reflexionan sobre temas clave en educación desde una perspectiva académica o que deliberan (evalúan o comunican) sobre la implementación de políticas estratégicas en el período. Aun cuando no se trata de informes de investigación, estos textos ayudan a contextualizar o exponer la investigación hecha.

La búsqueda de lo producido en el período bajo análisis se inició con la revisión de los más reconocidos catálogos de investigación educativa. El criterio de inclusión fue el año de publicación de los informes, al margen 
que se tratase de estudios hechos o iniciados en años anteriores al 2007. Las entrevistas a académicos y tomadores de decisiones en el sector permitieron identificar algunos estudios adicionales que también fueron incluidos en el balance, Luego, se procedió a registrar los textos seleccionados en fichas especialmente diseñadas para consignar información clave: título del estudio, autor/es, institución responsable, año de publicación, propósitos del estudio, diseño metodológico, principales resultados y propuestas de política, de haberlas. Por último, sobre la base de estas fichas, el balance se organizó en temas generales y otros más específicos.

Sólo resta decir que el balance aquí presentado es un registro analítico de parte importante de la investigación hecha en educación y no tiene como propósito evaluar su calidad.

\section{Balance de investigación}

\section{Marcos institucionales de investigación y vinculaciones con políticas.}

Más de la mitad de los 52 estudios considerados en este balance se realizó en organismos no gubernamentales (ONG) o espacios de reflexión y propuesta como el Consejo Nacional de Educación (CNE), el Consorcio de Investigación Económica y Social (CIES) o la Sociedad de Investigación Educativa Peruana (SIEP). Entre los primeros, el Grupo de Análisis para el Desarrollo (GRADE) llevó adelante 19 de esos estudios, con reflexiones centradas en la identificación de los factores asociados a los rendimientos escolares, aunque también abordaron otros procesos pedagógicos y de gestión, en algunos casos con recomendaciones explícitas de política u otras propuestas a nivel institucional. ${ }^{4}$

Un número importante de estudios, aunque significativamente menor al que corresponde a las ONG, se hizo desde las universidades y centros

\footnotetext{
4 La labor de GRADE en la investigación educativa en el país merece un comentario aparte. Se trata de una institución que no sólo ha producido una cantidad importante de estudios en el periodo observado y en años anteriores, sino que también es reconocida como un importante think tanks en el tema de las evaluaciones del rendimiento escolar. Entre 1998 y 2002 produjo conocimiento y evidencia en cantidad importante sobre el tema, y desarrolló una intensa labor de incidencia a favor de la incorporación del modelo de criterios en sustitución del modelo de normas en las evaluaciones nacionales del rendimiento llevadas a cabo por la Unidad de Medición de la Calidad de la Educación (UMC) del Ministerio de Educación (MINEDU) (Botto 2011).
} 
de investigación universitarios, mientras una cifra más baja, sobre todo evaluaciones de la implementación de políticas o de programas considerados estratégicos en el sector, estuvo a cargo de organismos internacionales.

El CIES desarrolló directamente o auspició con ONG y universidades 11 investigaciones, parte de ellas en el marco de los concursos de investigación que este Consorcio promueve. La SIEP ${ }^{5}$ ha publicado 17 artículos en los tres números de su revista de investigación en formato electrónico, cuatro de ellos registrados en este balance.

Los estudios aquí consignados pueden dividirse entre los que hacen recomendaciones de política pública o institucional y los que no lo hacen. Los primeros -aproximadamente un tercio del total- pueden dividirse, a su vez, entre aquellos explícitamente diseñados para la formulación de recomendaciones de política -la minoría- y aquellos que, dando prioridad a la producción de conocimiento, rematan con la presentación de algunas recomendaciones de política --la mayoría--. Cabe señalar que el abordaje de esas recomendaciones de política es muy diverso, en un abanico que va desde recomendaciones generales hasta otras muy concretas y ligadas al corto plazo.

\section{Orientaciones metodológicas.}

Los estudios registrados son de tipos muy diversos, de acuerdo con la orientación metodológica suscrita por cada uno de sus autores. Los más comunes son los descriptivos, que observan las prácticas docentes en sentido amplio (aula, currículo o escuela) o las prácticas de gestión a niveles micro. Utilizan muestras intencionales pequeñas, por lo general compuestas de los principales actores educativos (docentes, estudiantes, directivos o padres de familia), a quienes se aplica técnicas como la entrevista, los grupos focales o la observación de ambientes escolares. El análisis que realizan es predominantemente cualitativo, aunque en algunos casos se incorpora elementos del análisis cuantitativo.

Ligeramente menos frecuentes son los estudios con diseños estadísticos complejos (modelos lineales jerárquicos o de regresión) que utilizaron bases

5 La SIEP viene desarrollando una importante labor de apoyo a la producción sistemática de teoría y de evidencias, con fines de profundizar en el conocimiento sobre la educación en el país y de aportar a la formulación y debate de las políticas en el sector. 
de datos públicas (evaluaciones censales de estudiantes, censo escolar) o privadas para la observación de los factores asociados al rendimiento escolar y la asistencia/deserción, o para el examen de los retornos económicos de la inversión en educación. En estos casos el análisis es típicamente cuantitativo.

Aunque en cantidades menores, identificamos otros tres tipos de trabajos. Los primeros son los estudios de caso, que principalmente observan los cambios producidos en la escuela y otros espacios de la institucionalidad educativa local o regional tras la introducción de nuevos marcos de gestión institucional o intervenciones de distinto carácter. El análisis empleado en estos estudios es predominantemente cualitativo.

Los segundos son estudios de comparación con distintos diseños, entre ellos diseños longitudinales (observan los hechos en diferentes momentos para establecer cambios en los valores), diseños experimentales (comparan desempeños entre grupos) y las típicas evaluaciones de efectos (contrastan los resultados previstos y los alcanzados por una intervención puntual). Sus análisis son cuantitativos y cualitativos, con énfasis en los primeros.

Los terceros son estudios de fuentes secundarias, algunos de los cuales no son típicamente informes de investigación, pero, como se señaló en la introducción, han sido tomados en cuenta porque permiten contextualizar o facilitar la exposición de los resultados de la investigación realizada.

\section{Temas investigados.}

Una rápida revisión de la investigación consignada en este balance da inmediata cuenta de su particular composición: la totalidad de los estudios se ocupa de la educación formal y sus instituciones, dejando de lado espacios y procesos importantes de la educación no formal. Sólo cinco de los estudios observan el papel de la familia en los procesos de aprendizaje escolar, mientras otro espacio educativo importante como los medios de comunicación no aparece con un estudio registrado en el período. El grueso de los estudios giran en torno de la educación básica y apenas seis se refieren a procesos que tienen lugar en la educación superior universitaria y no universitaria. Otras concentraciones menores de estudios se dedican a la observación del nivel primario y la escuela rural. 
Sin embargo, al margen de la composición y las concentraciones mencionadas, los temas son diversos y tratados desde distintas aproximaciones conceptuales y metodológicas. Esto refleja la complejidad propia de los hechos educativos y que exige tener especial cuidado al proponer la clasificación de los temas, que definitivamente es sólo una entre otras muchas posibles.

La clasificación que planteamos comprende seis temas generales. Dentro de algunos de ellos hay otros más específicos, desarrollados cuando lo consideramos necesario. Los temas generales son los siguientes:

- Factores asociados al rendimiento y la asistencia escolar.

- Formación docente.

- Prácticas docentes y desempeño en aula.

- Recursos para el aprendizaje.

- Descentralización de la gestión educativa y participación.

- Financiamiento y retornos de la educación.

Podría decirse que la investigación registrada ha abordado -o por lo menos ha tocado- algunos de los más importantes temas en educación, que son además los temas en torno a los que se ha estructurado el debate público en los últimos años: la descentralización de la educación, la formación docente y los rendimientos escolares.

Quedan, sin embargo, algunos vacíos. El desarrollo profesional del docente, la participación de la familia en el aprendizaje y las prácticas pedagógicas en aula, temas importantes en el debate público y la agenda de políticas, fueron abordados en pocos estudios o de manera tangencial. La primera infancia y la evaluación de la educación superior, tanto universitaria como no universitaria, no fueron objeto de análisis.

En cuanto a la agenda de investigación propuesta por Cuenca (2008), los estudios realizados durante el período que abarca este balance (2007-2011) la han recogido en buena medida, principalmente los factores asociados al aprendizaje, la descentralización educativa y la cuestión docente como tema general. La escuela rural, otro de los puntos de dicha agenda, no ha sido 
tema de investigación, pero sí muchos de los estudios (más o menos la cuarta parte) han tomado a las escuelas rurales como unidades de muestra para observar procesos más específicos que se producen en su interior.

\section{Factores asociados al rendimiento y la asistencia escolar.}

La calidad de la educación recibida por los estudiantes ha sido evaluada desde distintas dimensiones. Una de esas dimensiones, quizá la más estudiada, es el rendimiento escolar. Los resultados de las evaluaciones censales de estudiantes (ECE) con pruebas estandarizadas muestran rendimientos muy pobres en general y a la vez muy desiguales. Según la ECE 2010, los aprendizajes que se espera alcancen los niños y niñas del $2^{\circ}$ grado son logrados sólo por el $28,7 \%$ en comprensión lectora y el $13,8 \%$ en matemáticas. Los resultados también muestran la existencia de brechas entre diferentes grupos. En comprensión lectora, la brecha urbano-rural es de $27,9 \%$ y la brecha estatal-no estatal de $25,8 \%$. En grupos más específicos como niños y niñas pertenecientes a minorías étnicas, los porcentajes de logro se reducen drásticamente: $6,9 \%$ en niños y niñas quechuas, 4,9\% en awajunes ó $1 \%$ en aimaras, configurando brechas aún más marcadas.

Al respecto, Miranda (2008, p. 11) sostiene que:

Los resultados de las evaluaciones nacionales e internacionales muestran que el grueso de la población escolar de nuestro país, y de sus similares de la región latinoamericana, no alcanza los estándares requeridos en competencias básicas de aprendizaje. En efecto, esta evidencia indica que los esfuerzos realizados durante los últimos años o no han ido en la dirección correcta o no han sido suficientes para que el sistema educativo se aproxime al cumplimiento de su objetivo central: asegurar de modo equitativo no solo el acceso al sistema, sino también el logro de aprendizajes que permitan a las personas, como individuos y como colectividades, desarrollar sus capacidades y potencialidades, así como enfrentar los desafíos del mundo actual.

¿Qué factores pueden estar incidiendo en los pobres resultados de nuestros niños y jóvenes en comprensión de lectura y matemáticas? ¿Qué nos dice la investigación hecha sobre el tema? 


\section{Factores asociados al rendimiento.}

Los factores asociados al rendimiento escolar han sido tema frecuente de la investigación educativa nacional en los últimos diez años. Bajo una lógica de sistematización de lo obtenido por la investigación en el campo, Cueto (2007), utilizando la técnica de meta-análisis, se propone identificar aquellas variables que muestran una asociación significativa con el rendimiento. ${ }^{6} \mathrm{Su}$ revisión incluyó veintidós estudios (trece en el área de matemáticas y nueve en comunicación), con el común denominador de haber utilizado las bases de datos de la UMC correspondientes a las evaluaciones nacionales de 1996, 1998 y 2001.

Los resultados de las variables directamente relacionadas con los estudiantes muestran que los alumnos con extraedad y/o que repiten alcanzan menor rendimiento que sus pares en la edad para el grado en todas las investigaciones. Igualmente, en todos los estudios los estudiantes que trabajan alcanzan un relativo menor rendimiento comparado con el rendimiento de los que no trabajan. Los estudiantes hombres logran mayores rendimientos en matemáticas que las mujeres en los trece estudios en esa área. El nivel socioeconómico del estudiante (característica de la familia) es una variable que muestra una fuerte asociación con el rendimiento, aun cuando los estudios no han utilizado definiciones iguales sino similares.

En lo que respecta a las variables que son parte del ambiente escolar o del aula, los resultados muestran que el nivel socioeconómico promedio de los alumnos que integran un aula se asocia positivamente con el rendimiento en todos los estudios, hallazgo que sugiere que este factor es importante más allá de las características individuales del estudiante. Sin embargo, otras variables del ambiente escolar, como el porcentaje de las competencias curriculares desarrolladas en el año, el contar con un proyecto curricular de centro en la escuela o la ayuda que puedan brindar los padres a sus hijos al momento de revisar las tareas escolares, muestran una asociación positiva en pocos estudios o sólo en una de las áreas observadas (matemática y comunicación).

$6 \quad$ Cueto explica que "....es una técnica (...) consistente en incluir en un análisis estadístico los resultados de varios estudios sobre una misma variable. El supuesto es que si bien un estudio puede resultar engañoso, la acumulación de estudios bien diseñados debería brindar evidencia sobre la "verdadera" relación entre variables" (2007: 424). 
Benavides y Rodríguez (2006a), en un análisis de los resultados de las evaluaciones de la UMC del MINEDU, ${ }^{7}$ llegan a tres conclusiones. La primera es que una parte importante de la disparidad de los rendimientos se explica por diferencias entre los estudiantes, es decir, la efectividad de las escuelas en lograr los aprendizajes se ve muy limitada por factores que se definen fuera de éstas, como las características de las familias de los estudiantes.

La segunda conclusión es que, en lo que concierne a la variabilidad asociada a las diferencias entre escuelas, las variables que definen sus características -como la ubicación (región natural, área), las características institucionales (tipos de gestión, de centro educativo) y la composición del alumnado (composición socioeconómica, incidencia de la repetición y de la desnutrición)- en conjunto explican el 50\% del 56\% o 59\% de la varianza demostrada en matemáticas, y $70 \%$ del $73 \%$ a $75 \%$ de la varianza demostrada en comunicación.

La tercera es que entre las variables que explican las diferencias entre las escuelas, las que son propiamente escolares como el equipamiento (acceso a recursos educativos) y los procesos educativos (manejo de contenidos curriculares, carga docente, preparación de clases) son las de menor participación, explicando sólo entre $3 \%$ y $4 \%$ de la varianza. ${ }^{8}$

Los estudios hechos en el periodo (2007-2011) confirman la importancia de variables como el nivel socioeconómico de las familias y la composición socio-económica de las aulas (ambas son variables que se definen fuera de las escuela) en la explicación de los rendimientos escolares. Al respecto, Carrasco (2007) realiza un estudio multinivel (estudiante, aula, escuela) sobre un segmento de la base de datos de PISA 2000, y encuentra que los estudiantes con mayor nivel socioeconómico alcanzan rendimientos por encima de la media de la escuela y que el atraso escolar está ligado al nivel

\footnotetext{
7 Este análisis también incluye el estudio antes mencionado de Cueto (2005).

8 Uno de los hallazgos de la investigación sobre factores asociados al rendimiento escolar es que los factores no escolares, como el nivel socioeconómico de las familias de los estudiantes, son muy importantes en la explicación de las variaciones en los rendimientos, como también lo habían establecido Benavides y Rodríguez (2006b) para un grupo de estudios en el tema hechos desde el CIES en la primera mitad de la década pasada. Es importante notar que entre las variables con mayor asociación a los rendimientos, las que se desprenden del nivel socioeconómico familiar son recurrentes al margen del universo de los estudios observados y de las bases de datos utilizadas en ellos.
} 
socio-económico y afecta, principalmente, a los estudiantes más pobres. Al comparar los resultados de escuelas con infraestructura en buenas y en malas condiciones, también constata que los rendimientos son favorables en las primeras pero que la ganancia no es homogénea para todos. Los estudiantes con mayor nivel socioeconómico se benefician más de esa situación, incrementándose las diferencias en rendimiento entre estudiantes de distintos estratos.

Miranda (2008) realizó otro estudio multinivel (estudiante, escuela) utilizando los resultados de las evaluaciones nacionales $(\mathrm{EN})$ del rendimiento estudiantil del 2001 y 2004..$^{9}$ Encontró que los rendimientos en estudiantes del $4^{\circ}$ grado en el área de comunicación se explican principalmente por diferencias en las escuelas, y que estas diferencias tienen a la composición socioeconómica de las aulas (característica derivada de las familias de los estudiantes) como la característica más influyente, incluso por sobre otras importantes como la satisfacción de los docentes con las escuelas y sus expectativas sobre el desempeño de los estudiantes.

Valderrama y Salgado (2010) arriban a resultados similares. Utilizando datos de la EN 2004, su propósito central era la observación de aquellas características del docente empleadas por la literatura especializada como variables que nos aproximan a la calidad de su desempeño. El estudio estableció que el nivel socioeconómico de la familia del estudiante -en este caso utilizada como variable de control-, se asocia de manera positiva y significativa con el rendimiento escolar, incluso con un efecto mayor que los distintos atributos observados en los docentes.

Por su parte, Miranda (2008) sostiene la necesidad de llevar adelante intervenciones particulares, específicas y focalizadas en grupos vulnerables, en sustitución de las tradicionales intervenciones universales que tienden a profundizar las desigualdades. Sostiene también que no hay por qué esperar que intervenciones estandarizadas tengan la misma efectividad en contextos y situaciones diversas.

$9 \quad$ Las EN 2001 y 2004 se hicieron sobre muestras de estudiantes a nivel nacional, constituyendo el antecedente inmediato de las ECE que son censales y se aplican anualmente desde el 2007. Estas evaluaciones y otras anteriores (1996 y 1998), realizadas con muestras más pequeñas, estuvieron a cargo de la UMC. 
Un segundo tipo de variables, que se presume asociadas al rendimiento educativo en la escuela, son los llamados "factores escolares". ${ }^{10}$ El estudio de Cueto et al. (2010), que utilizó un diseño longitudinal con datos recogidos en el 2000 y 2006 de una muestra de 304 estudiantes en Puno, sostiene que entre los factores propiamente escolares, el rendimiento previo es la variable que más se asocia con los rendimientos futuros. Los resultados sugieren que el rendimiento en una prueba estandarizada de matemáticas en $5^{\circ}$ grado es estadísticamente significativo en la explicación del rendimiento en matemáticas y en comprensión de lectura en $5^{\circ}$ de secundaria (seis años después), así como en la probabilidad que los estudiantes tienen de no repetir. Otro hallazgo relevante es que los resultados de la prueba se explican en gran parte por los antecedentes de rendimiento, pero sólo cuando éstos rendimientos son deficitarios.

Estudios de este tipo señalan la importancia de analizar la formación como un proceso dinámico y acumulativo, en la medida que el rendimiento previo se expresa de manera constante, incluso en el tránsito de la primaria a la secundaria. Señales adicionales --que es preciso observar más minuciosamente-- pueden indicar que las intervenciones en los procesos educativos alcanzarían mayor efectividad cuando los beneficiarios finales son niños y niñas de inicial o de los primeros años de la primaria.

Beltrán y Seinfeld (2011), en un estudio transversal (no longitudinal) que construyó --usando técnicas econométricas-un panel de datos basado en la ECE 2008 y el Censo Escolar para establecer la relevancia de las variables relacionadas a la oferta educativa sobre el rendimiento promedio en las escuelas, obtuvieron resultados consistentes con los de Cueto et al. (2010). Hallaron que, entre los determinantes del rendimiento en el área de comprensión de textos, las variables más influyentes son la proporción de alumnos que no repiten y la asistencia a la educación inicial. En el área de lógicomatemática, la proporción de alumnos que no han repetido el grado aparece nuevamente como la variable más significativa.

10 Los "factores escolares" son variables que en la investigación previa a nivel internacional han demostrado tener capacidad de explicación sobre variaciones en los rendimientos. Se ubican en tres niveles: la escuela (modelo de gestión, infraestructura, equipamiento, etc.), el aula (currículo implementado, ambientes de aprendizaje, rendimiento previo del grupo, etc.) y el docente (desempeño, compromiso profesional, uso efectivo del tiempo, etc.). 
En el caso peruano, la evidencia con respecto al efecto de la educación inicial en el rendimiento educativo es mixta (en unas investigaciones es positivo mientras en otras no), por lo tanto, como sostienen Cueto et al. (2010), no es concluyente. Sin embargo, cabe resaltar que para dos de los estudios presentados en este balance - Cueto et al. (2010) y Beltrán y Seinfeld (2011) - el efecto de la educación inicial es positivo.

Por su parte, Cueto et al. (2008) evaluaron los efectos de la asistencia docente sobre el rendimiento escolar en el marco del programa para una Mejor Educación con más Tiempo en el Aula (META), que entregó incentivos a los profesores con mayor asistencia. Encontraron que las diferencias en los rendimientos no son concluyentes al comparar grupos de tratamiento (con docentes incluidos en el programa) y control (con docentes no incluidos). Otro hallazgo importante fue que, al observar únicamente escuelas de tratamiento, la mayor asistencia docente sólo tuvo un efecto positivo en el rendimiento de los estudiantes en quinto grado, pero con un límite a partir del cual la mayor asistencia de los docentes no se traduce en un mejor rendimiento de los estudiantes.

Si bien esta clase de investigaciones ofrece evidencia empírica de los efectos del tiempo de exposición al aprendizaje en el aula sobre el rendimiento, sería necesario complementarlos con observaciones más detalladas de aquello que los docentes hacen con el tiempo en el aula, es decir, en qué lo utilizan y si ese uso es efectivo. Quizá esto permitiría establecer cuánto se puede explicar los rendimientos por el uso efectivo del tiempo docente y en qué medida estos efectos son comparativamente mayores (o menores) a los que se puede alcanzar con intervenciones orientadas a otras dimensiones en los procesos pedagógicos.

En su estudio, Cueto et al. (2008) reconocen la importancia de mantener los programas de incentivo a la asistencia docente, pero acompañados de otros componentes que podrían potenciar sus efectos. Recomiendan desarrollar en paralelo programas de profesionalización para que los docentes orienten mejor sus tareas, más aún considerando la evidencia que sugiere que las actividades pedagógicas de los docentes son rutinarias y de baja complejidad intelectual. 
Guerrero (2010) realiza una comparación entre una muestra de escuelas comprendidas en el programa de Educación Intercultural Bilingüe (EIB) y escuelas monolingües en Puno utilizando modelos de regresión lineal múltiple. Luego de controlar todas las variables relevantes, constató que el programa EIB (quechua y aimara) tiene un efecto negativo importante en el rendimiento de los estudiantes, tanto en matemáticas como en comprensión de lectura, al compararlo con el de sus pares en otros tipos de escuela. Sugiere una mayor inversión sectorial para mejorar los insumos del programa, capacitando a los docentes con el propósito de volverlos realmente bilingües, sensibilizándolos sobre la necesidad de este tipo de programas y suministrando a las escuelas los materiales necesarios para una verdadera formación intercultural.

La revisión de los estudios sobre este tema permite comprobar dos situaciones: la importancia de los factores ajenos a la escuela, dato construido por la investigación acumulada en los últimos diez años y demostrado en anteriores balances de investigación (Cuenca 2008, Benavides y Rodríguez 2006a, Barrantes e Iguíñiz 2004), y la necesidad de continuar con la observación de los factores propiamente escolares, sobre los cuales se cuenta con información muy parcial y resultados poco consistentes.

\section{Factores asociados a la asistencia escolar.}

Otro campo de análisis abordado desde diseños de factores asociados es la asistencia a la escuela. Se pudo identificar tres estudios de este tipo en el periodo del balance: Pariguana (2011), Alcázar (2008) y Vargas y Zevallos (2009). En el más reciente (Pariguana 2011), tomando como fuente la Encuesta sobre Trabajo Infantil (ETI) de 2007, analiza el problema de la deserción escolar y la decisión de estudiar como parte de un proceso de toma de decisión simultánea. Según el autor, el gasto (proxy del ingreso) del hogar se asocia a la decisión de los adolescentes de estudiar o trabajar, en el sentido de que un gasto mayor en el hogar tiene una correlación positiva con la decisión de estudiar y una correlación negativa con la decisión de trabajar. En ese marco, los adolescentes de áreas rurales se encuentran en clara desventaja frente a sus pares urbanos, pues vienen de hogares con menor capacidad de gasto, con jefes de hogar con menor nivel educativo, características familiares que son determinantes en la decisión de estudiar o desertar. 
Alcázar (2008) utiliza un diseño similar para analizar la decisión de estudiar/trabajar en una muestra de jóvenes estudiantes y desertores de 370 centros poblados. Según el estudio, los problemas económicos familiares o la carencia de recursos para la matrícula y la compra de materiales son las principales causas del abandono de la escuela, mientras que el factor con mayor poder explicativo es la decisión de trabajar, directamente vinculada con los problemas económicos familiares.

Los estudios centrados en la observación de los factores de la demanda más fuertemente asociados al abandono de la escuela demuestran que los principales tienen que ver con carencias o limitaciones en los ingresos de la familia. Por ello, las primeras recomendaciones de política que se desprenden de estos apuntan a la implementación de programas de apoyo monetario condicionado a los hogares pobres que sirvan para aliviar las fuertes restricciones financieras y favorecer el destino de recursos a inversiones de más largo plazo como la educación. Si bien actualmente se cuenta con el programa Juntos, es necesaria una intervención específica enfocada en el trabajo infantil y juvenil. Una experiencia exitosa en este campo es el Programa de Erradicación del Trabajo Infantil (PETI) en el Brasil, que puede ser tomado como referencia para extraer lecciones y aprendizajes.

Desde una perspectiva distinta, Vargas y Zevallos (2009, p.4) sostienen que:

La necesidad de una mayor investigación sobre los factores que condicionan e impulsan a los estudiantes a desertar, se hace evidente al reconocer que la poca literatura para el caso peruano ha puesto un mayor énfasis en identificar cuáles son las características que determinan esta decisión desde un punto de vista estático. ${ }^{11}$

Estos investigadores realizaron un estudio longitudinal con una muestra de panel de la Encuesta Nacional de Hogares (ENAHO) para el periodo

11 Vargas y Zeballos identificaron sólo dos estudios que buscan demostrar los efectos de un evento no anticipado (shock) sobre la probabilidad de desertar de los estudiantes. Escobal y Ponce (2006) utilizaron un esquema de equilibrio general para identificar los posibles efectos del TLC sobre el nivel de ingreso de los hogares y, de allí, sobre las decisiones de inversión en capital humano, encontrando que la situación de los niños y niñas de zonas rurales es mucho más vulnerable ante el TLC que la de sus pares en zonas urbanas. Escobal, Saavedra y Suarez (2003), utilizaron datos de la Encuesta Nacional de Hogares (ENAHO) para simular los efectos de shocks económicos, entendidos como cambios en el gasto, ingreso o estatus laboral, encontrando que no tienen efecto sobre el atraso educativo y la deserción escolar. 
2001-2006, y encontraron que el choque con consecuencias más negativas es la muerte de alguno de los padres, seguido de la pérdida de empleo y el hecho que alguno de los padres sufra una enfermedad crónica o tenga un accidente grave. Hallaron también que las condiciones de los hogares que empeoran las consecuencias adversas de los choques modelados son el no tener acceso a crédito, que el padre no acceda a un sistema de pensiones o que la familia sea pobre.

\section{Formación docente.}

El docente es un actor estratégico que juega un rol central en cualquier proyecto de transformación de los procesos educativos. El desarrollo de las capacidades pedagógicas no sólo influye directamente en la mejora de las prácticas docentes cotidianas, sino que abre un conjunto de posibilidades para alcanzar efectos en los aprendizajes de los estudiantes y en la institucionalidad educativa. En ese sentido, el estudio de la formación docente es doblemente necesario: permite dar cuenta de lo que sucede en ese campo, contribuyendo a la producción sistemática de conocimiento pedagógico, y además utilizar ese conocimiento de manera pragmática en la toma de decisiones para mejorar las prácticas en el corto plazo.

En su estudio exploratorio de la documentación producida por los programas de capacitación docente impulsados por el Estado, Eguren, Gonzales y De Belaunde (2008) encuentran algunos cambios en las prácticas y concepciones de los maestros involucrados. Sugieren que el Plan Nacional de Capacitación Docente (PLANCAD) favoreció procesos de democratización en el aula y, en términos generales, mejoras en el clima de éstas, asociadas a un aprendizaje más autónomo. Las concepciones sobre el aprendizaje que manejan los docentes también experimentan cambios. Hoy, gran parte de los docentes entiende al aprendizaje como un proceso de facilitación centrado en el estudiante y vinculado al uso de metodologías activas.

Montero (2008), a partir de un análisis de los grandes programas de capacitación docente implementados en el país entre 1995 y 2006, encuentra que su oferta tuvo una cobertura variable en el número de docentes atendidos cada año y que sólo llegaron a cubrir a algo más de la mitad de las escuelas primarias del país. Estos datos sugieren que los programas no respondían a un plan definido con metas, programaciones y evaluaciones que tomase 
en cuenta todos los elementos necesarios para una atención de carácter universal. La autora concluye que la información disponible permite sostener que no contamos con un sistema de formación de docentes en ejercicio que garantice a maestros en distintas regiones y con diferente situación laboral la posibilidad de capacitarse de manera continua.

Tras dar una mirada general de la política docente del Gobierno aprista, Guerrero (2009) realiza un balance de las principales decisiones a 1,000 días de la asunción del poder: las evaluaciones docentes, las restricciones en el acceso a los institutos superiores pedagógicos y el nuevo programa de formación docente en servicio. Con relación al último tema, sostiene que el modelo presenta dos grandes limitaciones. La primera, originada en el hecho de no haber tomado las evaluaciones a docentes y a estudiantes como líneas de base para identificar los campos deficitarios y críticos. No se cuenta con información generada por estudios sistemáticos sobre las necesidades reales de la formación docente, por lo que el programa ofertado responde más a intuiciones que a un análisis minucioso de la demanda.

La segunda limitación, estrechamente vinculada a la primera, se refiere al uso de un enfoque que reduce y simplifica en extremo los campos en los que se debe desarrollar capacidades: la comunicación, la matemática y la didáctica. Esta mirada restringida no corresponde a los perfiles exigidos a los docentes en el Diseño Curricular Nacional (DCN), que incluye, además de las capacidades mencionadas, otras que tienen que ver con los valores profesionales y el desempeño ciudadano.

Finalmente, apoyándose en fuentes secundarias, Montero (2011) sistematiza lo hecho por los grandes programas de capacitación docente llevados adelante en el país desde 1995 en el componente del acompañamiento pedagógico, e identifica un conjunto de limitaciones en los programas tradicionales: su carácter masivo, homogéneo, impersonal y pasajero. Sostiene la necesidad de optar por una formación docente con estrategias de acompañamiento, como las que ya se viene aplicando con resultados identificables en algunas de las versiones más recientes de estos programas. Sobre la implementación de estos sistemas de acompañamiento, que suponen contextualizar los procesos formativos y llevarlos al escenario en que trabaja el maestro, propone un conjunto de decisiones organizativas: 
La organización y gestión del acompañamiento pedagógico requiere garantizar una sucesión de hechos concatenados que comprometen a la administración del sector en sus diferentes niveles de gobierno (...) La llegada de acompañantes -maestros calificados- a las escuelas, en las fechas indicadas, con los materiales requeridos y con los objetivos y planteamientos pedagógicos claros, supone que oportunamente se convocó y seleccionó a maestros idóneos para cumplir su función, que ellos fueron debidamente formados, que conocen las necesidades e intereses de los docentes con quienes van a trabajar y que maestros y directores están dispuestos a acoger al acompañante y a recibir su asistencia directa (...) La organización requerida para renovar y fortalecer los programas de formación en servicio supone, entre otras cosas, normas claras, recursos, estrategias temporales definidas para avanzar en cobertura, en ámbitos espaciales y en niveles, así como buena capacidad de gestión (Montero, 2011, p.158).

La autora también señala una serie de problemas (nudos críticos) que es importante mencionar: la escasez de docentes con el perfil adecuado y en cantidad suficiente para atender las necesidades de acompañamiento existentes en cada región, las dificultades para alinear la normatividad que rige el trabajo docente (contratación, nombramiento, remuneraciones, licencias, etc.) con las características de la función de acompañante, y la superposición de programas y actividades de formación que coinciden en un mismo ámbito (regional o local) y operan con lineamientos diferentes.

La revisión de lo investigado sobre el tema de formación docente en el periodo 2007-2011 nos permite sacar dos conclusiones. La primera, que casi no se ha investigado respecto de la formación inicial del docente. La segunda, que los estudios sobre los programas de formación continua se han centrado en las dificultades de implementación y ejecución (normas, recursos humanos, capacidades instaladas) y en la revisión de sus orientaciones (modelos de formación, énfasis pedagógicos), sin abordar la evaluación de sus efectos.

No deja de sorprender lo poco que se conoce sobre los impactos de estos programas en aspectos concretos como las prácticas pedagógicas en 
el aula, el uso que se les da a los textos o los rendimientos escolares, más aún teniendo en cuenta la importante inversión sectorial hecha en ellos.

También llama la atención que la Ley de Carrera Pública Magisterial, una política estratégica dentro del quinquenio aprista, no se la haya estudiado lo suficiente como para obtener evidencia sobre sus resultados iniciales. Sólo se ha podido encontrar dos artículos: uno de Rodríguez (2007) y otro de Cuenca y Stojnic (2008). Rodríguez (2007), sostiene que es preocupante observar cómo se formula la nueva ley, en un proceso que progresivamente viene eliminando elementos importantes presentes en anteriores versiones de la propuesta, como el período de acompañamiento pedagógico y vínculo entre méritos y remuneraciones. Cuenca y Stojnic (2008) se ocupan de las dificultades para alcanzar consensos entre el Estado y las instancias de representación gremial y de la sociedad civil, situación que se expresa en el carácter limitado e instrumental que se le dio a la participación de los docentes y otros actores educativos en el proceso de aprobación de la ley.

\section{Prácticas docentes y desempeño en aula.}

Ames y Uccelli (2008) examinan la práctica de cuarenta docentes de institutops superiores pedagógicos (ISP). Su estudio descriptivo encuentra un uso eficiente, coherente y serio del tiempo, así como la utilización de diversas estrategias que promueven el diálogo y la participación, aunque con distintos niveles de eficiencia. Estos hallazgos difieren de lo señalado anteriormente por Oliart (1996), quien observó patrones de interacción autoritarios, desaprovechamiento del tiempo y desidia en las prácticas. Sin embargo, Ames y Uccelli (2008), a pesar de sugerir posibles mejoras en el manejo de la didáctica y el uso del tiempo en aula, encuentran debilidades en las prácticas que aún no han podido ser superadas: poca claridad sobre los objetivos de aprendizaje perseguidos, que hacen perder sentido a las actividades como tales, un limitado manejo (y transmisión) de contenidos, y un escaso uso de fuentes directas y muy frecuente de separatas de baja calidad.

Ames (2008), en una evaluación externa de dos intervenciones educativas, obtuvo resultados consistentes con el estudio anterior en lo relativo a las limitaciones en el manejo de contenidos. El problema central (limitación principal) identificado en ambas intervenciones fueron las deficiencias de fondo en la formación inicial de los docentes involucrados, quienes no 
estaban preparados para enseñar lo que debían porque no manejaban los contenidos ni las metodologías adecuadas para trabajar con estos.

Aplicando encuestas a una muestra estadística de 235 docentes del área de Ciencia, Tecnología y Ambiente en la ciudad de Arequipa, Turpo (2011) intenta aproximarse a las concepciones y prácticas docentes en la evaluación de los aprendizajes. El autor descubre la coexistencia de concepciones y prácticas evaluativas que los docentes internalizan como muy estables y difíciles de cambiar, y otras concepciones y prácticas menos consolidadas que están en proceso de cambio. Es decir, en un mismo profesor se detectan concepciones coherentes con distintas perspectivas, que van desde las consideradas como tradicionales o provenientes del conductismo hasta las llamadas modernas que vienen de los constructivismos.

Por su parte, Zelaya (2011) realizó un estudio exploratorio de las percepciones de actores educativos clave sobre la formación inicial de docentes en un ISP público. Valiéndose de un análisis integrado de las funciones a nivel del perfil del egresado, halló que las percepciones asocian las fortalezas del docente al "saber hacer" y las debilidades al "saber pensar", siendo la función de investigación la menos desarrollada. Asimismo, encontró que una debilidad general percibida en las egresadas es su poca capacidad propositiva y sus dificultades de adaptación a los entornos laborales. Sugiere que sus desempeños son fuertemente influenciados por el medio o el ambiente institucional donde se desenvuelven.

Desde una perspectiva distinta, dos estudios que utilizan la teoría institucional en educación como marco de análisis, revelan que la "cultura de la escuela" 12 es un factor importante para entender cómo se procesa desde los docentes cualquier propuesta de cambio. El primero, de Neira y Benavides (2010), en un estudio de caso sobre los procesos de implementación de un programa de formación docente. Para los autores, los docentes son sujetos activos que procesan, valoran y tamizan, desde su experiencia, cualquier propuesta de cambio que llegue a la escuela, lo que lleva a encontrar diferencias importantes entre lo que aparece en el diseño de las intervenciones y lo que se termina haciendo. Recomiendan que las propuestas de cambio en la escuela

12 La "cultura de la escuela" se refiere a las dinámicas y organizaciones particulares que adquieren las escuelas, como resultado de la interacción de docentes con antecedentes y experiencias particulares, que se plasman en concepciones y prácticas institucionalmente definidas. 
vayan acompañadas de componentes de asesoramiento y monitoreo, que son espacios y procesos de acercamiento (conocimiento mutuo) que pueden desencadenar dinámicas con impactos positivos.

El segundo, es el de Arteta (2010), otro estudio de caso orientado a la comprensión del punto de vista de los docentes en las interacciones y respuestas ante una presión institucional externa. La autora sostiene que las creencias culturales de los docentes sobre qué constituye una escuela influyen en cómo se concibe su funcionamiento, el manejo del tiempo, qué materias deben impartirse y cómo, la planificación de actividades, entre otras decisiones. Recomienda que académicos y hacedores de políticas abandonen la percepción del docente como un ser pasivo y receptivo a las presiones institucionales externas, y la reemplacen por una bastante más real: la de un sujeto que construye y reconstruye los mensajes a partir de sus experiencias previas.

Con una perspectiva similar, Zevallos (2010) realiza un estudio cualitativo sobre la implementación del currículo de historia en dos escuelas privadas de Lima. Uno de sus principales hallazgos es que el pretendido afán del currículo oficial de guiar a todas las escuelas no se estaría cristalizando, debido a factores de carácter institucional y decisiones docentes. Sostiene que si esto ocurre en comunidades educativas socialmente homogéneas como las de las escuelas y entornos educativos limeños, resulta muy difícil pensar en un "discurso escolar" sobre nuestra historia que llegue a las escuelas en las distintas regiones y que pueda incidir de manera semejante en todas ellas. También afirma que, al margen de la ausencia de capacidades para la diversificación, existe cierta resistencia a incorporar insumos del currículo oficial en las implementaciones institucionales básicamente por decisiones de los docentes.

La sistematización de Cuenca (2011) toma como fuente de información los diálogos regionales con docentes en el marco de la Mesa Interinstitucional de Desempeño Docente del CNE y busca reconstruir los principales elementos con los que los docentes desarrollan nociones y discursos sobre sus prácticas en el aula. Según el estudio, el desempeño es entendido como un proceso cuya valoración es atribuible al nivel de presencia de un conjunto de características individuales y profesionales, donde el conocimiento sobre 
las materias enseñadas y el manejo didáctico se hacen efectivos en la medida en que los docentes estén dotados de liderazgo, habilidades comunicativas y compromiso profesional.

Resulta reveladora una idea recurrente en los docentes que concibe el conocimiento disciplinar subordinado al pedagógico. Pareciera que la definición del buen desempeño se construye sobre una práctica sustentada en un manejo óptimo de las metodologías y la didáctica. También es elocuente el valor positivo que se otorga a la participación, una noción fuertemente instalada entre los docentes. En el contexto de las estrategias participativas, se entiende que el buen desempeño pasa por promover la reflexión y la opinión propia de los estudiantes.

\section{Recursos para el aprendizaje.}

La ejecución del proyecto Una Laptop por Niño el año 2007 dividió a la comunidad involucrada en la reflexión sobre la educación en el país entre quienes, por un lado, junto a las autoridades del MINEDU, se mostraban muy entusiastas con el hecho de que la sola presencia de las computadoras en las aulas tendría efectos favorables en el aprendizaje de los niños y las niñas; $y$, por otro lado, quienes tenían reservas y argumentaban que las computadoras por sí solas no tendrían mayor incidencia si no iban acompañadas de capacidades docentes para incorporarlas como recursos de aprendizaje. Las primeras dos evaluaciones del proyecto parecen dar la razón a los segundos.

El estudio de caso de Laura y Bolivar (2009), que abarcó a las primeras escuelas rurales incorporadas al proyecto en el sur del país, encontró que los docentes no cuentan con las competencias necesarias para diseñar e implementar nuevos entornos de aprendizaje que incluyan el uso de las computadoras. Según lo observado, los maestros no conocen metodologías y estrategias de trabajo que permitan una adecuada utilización de estas máquinas, situación que los lleva a restringir su empleo a la reproducción de tareas tradicionales como el copiado de textos que antes se hacía en el cuaderno. Asimismo, que su dominio de los aspectos técnicos y la solución de los problemas de funcionamiento -que son frecuentes- de las computadoras no son suficientes, lo que lleva a que no puedan ser utilizadas. La conclusión general es que las computadoras no constituyen una verdadera innovación en la enseñanza, ni han generado cambios en 
las formas de organizar y llevar adelante las sesiones de aprendizaje. Sin embargo, identifican algunos efectos positivos derivados del proyecto, como un mayor acercamiento de los estudiantes a la tecnología, mejoras en la motivación, aumento de la participación en clase y mayor interés por asistir a la escuela.

Dos de las recomendaciones de las autoras tienen que ver con las capacidades de los docentes para incorporar estas tecnologías: (i) que las capacitaciones consideren las necesidades de los docentes y no se definan por la oferta de capacitación en tecnologías existente a nivel local o regional, como sugieren viene ocurriendo; y (ii) la necesidad de promover políticas institucionales sobre la integración de las computadoras en los procesos de enseñanza-aprendizaje.

La evaluación con diseño experimental de Santiago et al (2010) buscó explorar los impactos de la provisión de computadoras portátiles (con el modelo 1 a 1 ) en las prácticas educativas y los aprendizajes de los estudiantes de escuelas primarias rurales multigrado. Sus resultados son similares a los de Laura y Bolivar (2009): las computadoras portátiles se usan con regularidad (entre dos y tres veces por semana), pero asimiladas a prácticas docentes tradicionales. En buena parte de los casos, los estudiantes solo transcriban textos de los cuadernos o las pizarras a las computadoras para posteriormente editarlos. En lo que respecta a los posibles efectos en los aprendizajes, no se detectó diferencias significativas entre los resultados alcanzados por los estudiantes del grupo de tratamiento y los del grupo de control en las pruebas nacionales.

\section{Descentralización de la gestión educativa y participación.}

La descentralización de la educación es un proceso complejo, con componentes fundamentalmente políticos vinculados a las concepciones de actor educativo sobre lo institucional, lo local y el cambio en estos espacios. Por ello, no es extraño que el encuentro de actores con miradas distintas, que a su vez responden a experiencias previas, posicionamientos e intereses, resulte conflictivo y difícil.

Es importante no perder de vista que se trata de un proceso participativo, novedoso para los actores educativos, y distinto en términos de 
sensibilidades, capacidades necesarias y procedimientos respecto de aquello que convencionalmente se hacía.

En ese escenario, la investigación desempeña un rol clave no solo identificando limitaciones y nudos críticos, sino también potencialidades y buenas prácticas que ayuden al fortalecimiento de los procesos.

\section{Descentralización de la educación.}

El estudio de caso de Valdivia y Díaz (2008) sobre el funcionamiento de las Unidades de Gestión Local de la Educación (UGEL) buscó identificar los principales obstáculos que estas enfrentan para alcanzar una adecuada gestión en el nivel local. Sus hallazgos más importantes son: (i) la pesada carga administrativa en estas unidades y la escasez de recursos (especialmente la falta de personal) genera ineficiencia, limitando enormemente los tiempos y recursos disponibles para el cumplimiento de su principal función, la supervisión y la asistencia técnica a las instituciones educativas; (ii) un porcentaje importante de especialistas no cuentan con las capacidades técnicas y profesionales necesarias para el cumplimiento de sus funciones; (iii) el personal antiguo estable no muestra suficiente compromiso profesional; y (iv) no existen políticas claramente orientadas a la formación y capacitación del capital humano en estos organismos, lo que genera una oferta de servicios de muy pobre calidad.

Concluyen que intentar una solución a estos problemas transfiriendo las responsabilidades de financiamiento a las municipalidades probablemente llevará a que en unas localidades (aquellas con más recursos) la supervisión y la asesoría pedagógica a las escuelas funcionen mejor, mientras en otras (aquellas pobres y con recursos muy escasos) se verán muy limitadas o simplemente no ocurrirán, configurando un factor de mayor diferenciación.

$\mathrm{Al}$ evaluar las capacidades de los actores regionales para desempeñar las funciones que les corresponden en el marco del proceso de descentralización, Gonzales, De Belaunde y Eguren (2008), encuentran que la mayoría de funcionarios en organismos intermedios de la educación son docentes 
que no cuentan con las habilidades necesarias para gestionar instituciones de este tipo, y que, en la mayoría de los casos, no han recibido ninguna capacitación complementaria que les permita asumir, al menos con herramientas básicas, sus nuevas tareas. Al parecer, la designación de estos funcionarios sigue procedimientos poco claros. En algunos casos responde a criterios de reconocimiento al desempeño docente, mientras en otros a mecanismos de copamiento o de cupos políticos. No se observa prácticas claras e institucionalizadas de asignación de cargos basados en perfiles y competencias profesionales.

Con el propósito de diagnosticar el proceso de descentralización educativa desde la perspectiva del presupuesto, aunque también se ocupan de temas como la organización y las capacidades institucionales, Alcázar y Valdivia (2011) estudian los casos de tres gobiernos regionales (Piura, Loreto y Cusco) y seis gobiernos locales en esas regiones (tres de ellos incorporados en el Plan Piloto de Municipalización de la Gestión Educativa).

De acuerdo con lo observado, el proceso de transferencia de funciones es más formal que real debido a que no ha estado acompañado de la transferencia efectiva de recursos suficientes para el cumplimiento de las nuevas funciones. La mayor parte de los recursos se destina a cubrir gastos corrientes (pago de docentes, servicios públicos y gastos administrativos), sin posibilidad de orientarse a proyectos de inversión u otras iniciativas.

Un problema crítico identificado por los propios funcionarios regionales es la ausencia de personal con las capacidades necesarias para enfrentar los retos del nuevo proceso, cuya principal explicación sería las restricciones de carácter legal para adecuar las estructuras organizativas a las nuevas funciones y para la contratación de personal.

En el caso de las municipalidades la situación sería aún peor: en este nivel el tema educativo no es una prioridad que se exprese en una estructura organizacional y funcional específica, en un trabajo sistemático, en la distribución del presupuesto o en recursos humanos dedicados a la gestión de la educación local. Los gobiernos locales observados no cuentan con personal calificado ni disposiciones institucionales para hacer una verdadera gestión de la educación en sus jurisdicciones, problema que es aun más 
grave en aquellos incluidos en el Plan Piloto de Municipalización, que deben enfrentar nuevas funciones educativas para las cuales no están preparados.

Los tres estudios reseñados son concluyentes al señalar la evidente ausencia de recursos humanos calificados para asumir las funciones que el proceso de descentralización requiere en los niveles regional y local.

Por su parte, Uccelli (2008) estudia el desempeño de las instancias locales y de sus funcionarios en la implementación de políticas de atención a la infancia en el marco de los programas no escolarizados de educación inicial, y encuentra serias contradicciones entre los discursos y las decisiones tomadas. A nivel de discurso (políticas y normas), el MINEDU señala la necesidad de asegurar condiciones óptimas para la implementación de programas de este tipo, pero en la práctica la escasez de recursos en las instancias locales, la débil incorporación de los programas en la planificación de sus actividades, así como la asignación marginal de recursos específicos no lo permiten y, por ende, los logros alcanzados son mínimos.

En materia de autonomía escolar, una dimensión más acotada del proceso de descentralización, el estudio cualitativo de Cuglievan y Rojas (2008) explora los roles, funciones y niveles de participación de los principales actores en la gestión de la escuela. De acuerdo con las autoras, a cinco años de la aplicación progresiva de la norma no se ha conseguido modificar la estructura, dinámica y funcionamiento de las escuelas. Si bien los nuevos roles y funciones de los actores escolares establecidos en la norma definen una concepción renovada sobre la escuela, en la realidad esto no tiene un correlato en cambios concretos y perceptibles en los espacios escolares, especialmente en las aulas. Tampoco se ha logrado una comprensión cabal del sentido del Consejo Educativo Institucional (CONEI) como máxima instancia de gestión y, por ello, no se apoya lo suficiente su implementación o se le bloquea, en un contexto en que la voluntad de cambio es minoritaria y marginal. Concluyen que la débil apropiación de los nuevos roles y funciones por parte de los actores escolares lleva a que los cambios promovidos sean sólo formales. La autonomía escolar requiere del desarrollo de capacidades y actitudes en todos los actores involucrados, de prácticas de autoevaluación en las escuelas y de una estructura organizacional que contemple los recursos (humanos, tiempos, espacios) necesarios para sustentar los procesos de cambio. 
Montes (2010) realiza un estudio cualitativo de las percepciones de los distintos actores vinculados al proceso de descentralización educativa, e identifica problemas similares a los hallados por Cuglievan y Rojas (2008) en lo que respecta al desconocimiento y confusión sobre el sentido de la autonomía escolar. También recomienda el desarrollo en las regiones de capacidades de concertación, manejo de conflictos, gestión de la información y de diseño de propuestas, habilidades necesarias para impulsar procesos de este tipo que no poseen los actores observados.

\section{Procesos de participación.}

Stojnic y Sanz (2007) analizan el proceso de constitución y funcionamiento de una muestra nacional de Consejos Participativos Regionales (COPARE) con el objetivo de identificar oportunidades y nudos críticos. Según los autores, la normatividad que sustenta estas instancias es poco clara en orientaciones, mecanismos y procedimientos, lo que favorece una alta discrecionalidad entre los agentes del gobierno, a pesar de tratarse de espacios con representación mixta del Estado y la sociedad civil. Asimismo, los agentes gubernamentales muestran desinterés en la consolidación de los consejos, en unos casos porque no tienen la voluntad política para asegurar estos procesos, en otros casos por la sobre carga de funciones que supone la participación en tales espacios, frente a recursos humanos y financieros muy limitados. Por su parte, los representantes de la sociedad civil tienen un discurso favorable a la participación y la concertación política, pero en la práctica muestran escaso sentido de apropiación de los procesos y poco compromiso con su fortalecimiento.

Siguiendo una línea similar al trabajo anterior, pero observando procesos de participación a nivel institucional, Muñoz (2009) realiza un estudio cualitativo de los CONEI en Piura y Cusco. Encontró que las relaciones entre actores reproducen prácticas autoritarias y excluyentes que son parte de la vida cotidiana de la escuela. Peor aún, alguna evidencia sugiere que esta situación se expresa con más nitidez en las escuelas de las zonas rurales, donde los niveles de exclusión y pobreza son mayores. En opinión de la autora, en las escuelas y en sus entornos aún no existen las condiciones estructurales necesarias para favorecer la participación efectiva e igualitaria de los actores. 
El estudio cualitativo de Balarín y Cueto (2008) se ocupa de lo que los padres de familia y maestros entienden por participación de las familias en el aprendizaje. Los resultados evidencian que los primeros tienen una comprensión limitada de cómo se produce el aprendizaje en las escuelas y cómo pueden apoyar a sus hijos en ese propósito, especialmente los padres de las familias más pobres y menos educadas. Asimismo, que casi ninguna escuela cuenta con estrategias para orientar la participación de los padres o para canalizarla en espacios más o menos identificables. Los autores plantean la necesidad de políticas claras y de estrategias para fomentar y modelar la participación de los padres de familia en el aprendizaje de sus hijos. Es necesario también mejorar las capacidades instaladas en las escuelas para involucrar a los padres en la gestión, a fin de establecer líneas de colaboración familia-escuela y de cerrar las brechas entre ambas.

Benavides, Rodrich y Mena (2009) analizan la relación entre dinámicas familiares y escolaridad, profundizando en las características de la participación de los padres de familia en actividades vinculadas a la escuela y en los procesos de asignación de tiempo familiar a actividades educativas fuera del horario escolar. Utilizaron una base de datos del proyecto EduCal con escuelas de 10 comunidades con distintas características geográficas (zonas altas y bajas, rurales y urbanas) en la provincia de Quispicanchis, Cusco.

Los investigadores encontraron un marcado contraste entre lo heterogéneo del tiempo que los padres destinan a acompañar las actividades educativas de sus hijos fuera del horario escolar y la homogeneidad en su tasa de participación en espacios como la Asociación de Padres de Familia (APAFA), diferencia que sugiere que se trata de procesos distintos de relacionamiento de las familias con las escuelas. Otro hallazgo importante es que, en general, estas interacciones entre padres y profesores no se plasmarían en herramientas claras que los padres puedan utilizar para influir positivamente en los procesos de aprendizaje propuestos desde la escuela. Asimismo, que el tiempo empleado por los niños y las niñas en actividades educativas fuera del horario escolar es mínimo, y que los casos de menor asignación parecen asociarse a familias quechua hablantes que habitan en zonas altas y cuyos hijos dedican mayor tiempo a actividades laborales en el campo. 
De la revisión de los informes emerge, con distintos niveles de claridad, una conclusión general: una normatividad favorable no garantiza la participación sino va acompañada del desarrollo de capacidades para la gestión participativa, de sensibilización sobre las ventajas de este tipo de procesos y de políticas locales que apunten a revertir el clientelismo y el verticalismo, que son las formas tradicionales de hacer política en los ámbitos locales que desde hace mucho han permeado el funcionamiento de las escuelas y de otras instituciones educativas.

\section{Financiamiento y retornos de la educación.}

\section{Financiamiento de la educación.}

En un estudio de fuentes secundarias basado en los resultados de las ECE y de estadísticas del gasto público en el Sistema Integrado de Administración Financiera (SIAF), Rodríguez y Garro (2011) encuentran que la correlación entre el ranking regional del rendimiento escolar construido desde las ECE y el gasto por alumno en las regiones es positiva y significativa, de lo que extraen dos conclusiones. La primera, que las regiones donde los estudiantes alcanzan mejores resultados son aquellas en las cuales el Estado ha gastado más por alumno (Moquegua, Tacna, Lima), con excepciones como Tumbes o Apurimac, con gastos por encima del promedio y rendimientos bajos o muy bajos. En el otro extremo de la distribución, los menores gastos públicos en educación coinciden con los más bajos rendimientos, como los casos de Ucayali, Huanuco o Loreto. La segunda conclusión pone en relieve el hecho de que no se ha utilizado políticas de discriminación positiva para concentrar mayores recursos en las regiones con rendimientos más bajos. Ello habría llevado a que, dependiendo de la cantidad de recursos asignados para estos casos, la correlación sea menos significativa o que incluso se torne negativa.

En su estudio, Garfias (2009) busca establecer las razones del uso con otros propósitos de los recursos provenientes del canon que ingresaron al presupuesto de las universidades públicas para incentivar la investigación científica y tecnológica ligada al desarrollo regional. De acuerdo con lo observado, esos fondos se destinan al incremento de sueldos de los docentes ordinarios a través de la figura de "bonificaciones por investigación", asociadas a "productos" que no están sujetos a seguimiento o control de calidad alguno. Tal situación es consecuencia de las pobres capacidades 
institucionales para la investigación en las universidades y de las deficiencias en la organización para la producción de ciencia y tecnología, condiciones que pasaron por alto los actores políticos que decidieron otorgarle estos fondos a las universidades.

El autor propone destinar parte importante de los fondos del canon a fortalecer las capacidades en investigación y la organización para la investigación en las universidades públicas, en el marco de la política nacional de investigación que se viene implementando.

\section{Retornos de la educación.}

En materia de retornos en la educación, Calónico y Ñopo (2007) realizan un estudio analítico de regresiones con datos de la Encuesta Nacional de Niveles de Vida (ENNIV) de 1997 y 2000. Para los investigadores, la mayor diferencia en los retornos entre la educación pública y privada (favorable a esta última) se da en los niveles primario y secundario. También sostienen que las diferencias han venido creciendo para las generaciones más jóvenes, mientras que las cohortes más viejas no muestran diferencias significativas. Afirman que esta brecha podría estar creciendo debido al deterioro de la calidad de los servicios educativos provistos por la escuela pública, y de las condiciones socioeconómicas de los niños y jóvenes que asisten a estas escuelas, que cada vez son los más pobres.

Por su parte, al evaluar los retornos de la educación superior en el mercado laboral, en un estudio de regresiones que utiliza datos de la ENNIV y la ENAHO, Yamada (2006) encuentra que la educación superior no universitaria pública otorga tasas de retorno privado y social muy poco atractivas, las que incluso resultan inferiores a las mejores rentabilidades ofrecidas por ahorros a largo plazo en el sistema financiero peruano y a la rentabilidad de los proyectos que aprueba el Sistema Nacional de Inversión Pública (SNIP). Su propuesta es que el Estado brinde mayor información acerca del mercado de la educación superior, para que los jóvenes y los padres de familia tomen mejores decisiones sobre el tipo de educación superior y la carrera específica que deben escoger. Una primera medida al alcance de la mano sería incluir de ahora en adelante y de manera permanente en las ENAHO una pregunta acerca de la profesión específica estudiada (adicional a las preguntas sobre el máximo nivel 
educativo alcanzado), para realizar un adecuado empate con la profesión efectivamente desempeñada en el mercado laboral.

\section{Agenda de investigación}

La agenda de investigación ha sido construida con insumos diversos y de distinto tipo: las agendas de investigación elaboradas para el CIES en los períodos anteriores (Barrantes e Iguíñiz, 2004; Cuenca, 2008); un balance de investigación (Benavides y Rodríguez 2006b); un grupo pequeño de entrevistas con investigadores, y un taller de discusión y validación del balance y la agenda (en versiones previas) con directivos del MINEDU. Gran parte de estos insumos están plasmados en los temas que se presentan en seguida.

\section{Vinculación de la investigación y evidencia de políticas.}

La agenda no debe limitarse a la exposición de un listado de temas prioritarios que deben ser objeto de investigación. Es necesario reflexionar y tomar decisiones sobre qué tipo de investigación debe ser priorizada, dado su valor en la producción de evidencia que apoye la formulación de políticas públicas.

Se sabe que la investigación experimental y los estudios multinivel que emplean modelos estadísticos complejos son dos de los diseños de investigación con mayor aceptación si se trata de identificar evidencias. Se sabe también que los estudios que gozan de mayor estatus en ese campo son los meta-análisis hechos sobre los resultados de investigaciones que utilizaron diseños experimentales y multinivel. Es lógico pensar que parte importante de los recursos y los esfuerzos de investigación deben seguir esas rutas y propósitos.

En este punto cabe preguntarse: ¿Qué se está haciendo para generar y diseminar las capacidades necesarias para hacer investigación con diseños complejos? ¿Cuál es el estado del arte de la evidencia producida por la investigación nacional? ¿Qué capacidades tenemos hoy para hacer investigación vinculada a la producción de evidencias? ¿Cuáles son estas capacidades en las regiones y en qué medida se pueden apropiar de una agenda macro y contextualizarla? ¿Cuáles deben ser las metas de investigación a mediano plazo y qué retos se desprenden de ellas? 
Lo expuesto no debe inhibir la iniciativa de emprender otros tipos de estudios, quizá más acotados a casos y que deben ser abordados en profundidad, indispensables para observar situaciones que se presentan a niveles micro o que responden a contextos muy particulares.

En la presentación que sigue de los temas priorizados, se incluye apuestas por temas puntuales y algunas sugerencias sobre la necesidad de mantener la diversidad de metodologías y enfoques.

\section{Factores asociados al rendimiento escolar.}

Es necesario continuar observando los factores que explican los rendimientos escolares. En el período que abarca este balance -y en los correspondientes a los anteriores- se ha hecho una buena cantidad de estudios con resultados consistentes que identifican características de las familias de los estudiantes (niveles socio- económicos principalmente, pero también disponibilidad de ambientes adecuados para el estudio, educación de los padres o presencia de la madre) como variables que explican diferencias en los rendimientos. Sin embargo, se sabe poco de aquellos factores que son parte de la escuela y que la evidencia internacional reconoce como variables que también tienen incidencia en los rendimientos. Asimismo, es poco lo que se conoce de los roles que juegan las familias en los procesos de aprendizaje.

Tendríamos que preguntarnos si estos espacios intervienen en la generación de buenos o malos desempeños. En el caso de las escuelas, imaginamos interrogantes sobre la proporción de los que repiten año en el aula/escuela, el desempeño docente en el aula, la efectividad del uso del tiempo en la docencia, el clima institucional, los materiales educativos y su uso, entre otros. En el caso de las familias, sólo se ha observado dimensiones socioeconómicas (ingresos, gastos, educación de los padres) en una perspectiva muy restringida que es necesario ampliar y diversificar.

Una ruta posible y sin duda muy productiva es la que emprendieron Alcázar y Cieza (2002). Al comparar escuelas de Fe y Alegría con escuelas públicas similares, encontraron que las primeras logran mejores resultados. Una parte de la explicación descansa en el hecho de que son escuelas con mecanismos de supervisión efectivos, profesores más motivados, o con acceso a recursos adicionales a los del Estado, variables estas que podrían 
considerarse como indicadores de una mejor gestión. Otra parte de la explicación se encuentra, según los autores, en la mayor responsabilidad y compromiso de los padres de familia de estas escuelas, situación que lleva a plantear la probabilidad de que sus hijos sean también estudiantes responsables y los mejores en la zona.

Se sugiere trabajar una línea de estudios de caso en profundidad que observe casos exitosos en escuelas, buscando establecer qué funciona, que participación tienen las familias en ello y cuáles son los disparadores de esos círculos virtuosos.

\section{Evaluación de programas de formación docente.}

A pesar de la importante inversión pública en programas y otras experiencias de formación docente en los últimos dieciocho años, en el país no se ha hecho evaluaciones confiables sobre el impacto de las capacitaciones en aspectos concretos como los rendimientos escolares, las prácticas pedagógicas en el aula, el uso de los textos de formación o la incorporación de las tecnologías en los procesos de aprendizaje.

Es necesario evaluar el papel cumplido por algunos componentes de los programas de formación, como el acompañamiento pedagógico a los docentes. Preguntarse en qué medida estos sistemas de acompañamiento y monitoreo resultan en mejores prácticas pedagógicas de los docentes. Es importante extraer aprendizajes y lecciones sobre aquello que se ha hecho bien y lo que ha resultado deficiente, aprovechando lo primero y tratando de superar lo segundo.

También se requiere evaluar los mecanismos para articular la formación docente a políticas integrales de desarrollo profesional del docente.

\section{Prácticas pedagógicas.}

Lo poco que sabemos acerca de lo que sucede en el aula sugiere que las prácticas docentes siguen siendo expositivas y frontales, las programaciones muy débiles, el manejo de contenidos y didácticas limitado, y la evaluación restringida a calificar, sin retroinformación ni construcción de aprendizajes. Asimismo, que los docentes enseñan cosas muy sencillas frente a lo que se esperaría dado el currículo nacional o lo que se evalúa en las ECE. 
Cambiar esta situación requiere una acción concertada en varias dimensiones, así como políticas de desarrollo profesional del docente que abarquen todos sus momentos: cómo atraer y retener a los mejores docentes, cómo desarrollar programas de formación inicial y en servicio que sean eficaces y eficientes, cómo desarrollar evaluaciones del desempeño confiables y válidas, cómo desarrollar sistemas de monitoreo y acompañamiento que resulten en mejores prácticas pedagógicas. Sería muy beneficioso contar con investigaciones que evalúen estos procesos e identifiquen las mejores prácticas para intentar generalizarlas y las deficitarias para no repetirlas.

\section{Descentralización de la educación.}

La descentralización educativa viene siendo promovida bajo el supuesto de que la combinación de autonomía, participación y puesta de relieve de los intereses locales debe llevarnos a mejores decisiones, procesos más transparentes y garantías en la administración de los recursos. Se estima que estos logros, en conjunto, crearían condiciones para que los sistemas educativos locales alcancen las metas esperadas en mejores desempeños y reducción de las desigualdades.

Sin embargo, lainvestigación sehalimitadoa observar la descentralización como proceso desde una perspectiva organizacional y normativa. No se ha analizado sus efectos en la gestión de la escuela (indicadores de gestión), en el currículo (tercio curricular y diversificación) o en las condiciones de vinculación escuela-familia.

\section{Como sostienen Benavides y Rodríguez (2006b, p.17-18):}

...la evidencia internacional no es concluyente sobre los beneficios de la descentralización. Si bien existen estudios que sostienen una relación positiva entre descentralización y logros académicos y descentralización y reducción de desigualdades educativas, otros sugieren una relación negativa.

Urge levantar un estado del arte sobre los alcances y límites de los modelos de descentralización puestos en práctica en otros países de la región, para identificar aquello que funciona ( $\mathrm{y}$ en qué condiciones lo hace) y aquello que no, en la lógica de ir clarificando las rutas de un proceso que es en esencia complejo. También es urgente realizar diagnósticos y trazar líneas de base en 
cada espacio local o regional, con la finalidad de tener referentes que permitan establecer si se avanzó y cuánto. A nueve años de iniciado el proceso, ya es momento de contar con alguna evidencia nacional sobre sus resultados.

\section{Participación de la familia.}

La investigación hecha sobre las vinculaciones escuela-familia en el país no sólo es escasa, sino se ha limitado a observar el rol de los padres en los espacios de participación escolar. No se ha analizado (o se ha hecho de manera muy acotada) cómo y cuánto se involucran los padres en la facilitación y el apoyo a las tareas escolares cotidianas de sus hijos, que son las actividades que más se asocian a los aprendizajes según la evidencia existente.

Cada vez es mayor evidencia acerca del hecho de que las familias importan en los desempeños educativos tanto como las escuelas. Por ello, la política educativa no puede ser concebida únicamente en términos de lo que ocurre en las escuelas. La observación de los procesos formativos no se debe limitar a la escuela, sino que debe considerar sus vinculaciones con las familias.

El estudio de Bello y Villarán(2009), que hace jugar los contextos (sociales, culturales, familiares) en los que se llevan a cabo las prácticas educativas en la explicación de las formas que estas adquieren, define una línea de trabajo interesante y con mucho potencial para la producción de conocimiento.

\section{Educación superior universitaria y técnica.}

En los últimos veinte años hemos presenciado la proliferación de nuevas universidades, institutos y programas de formación de dudosa calidad. Frente a esa situación, en la segunda mitad de la década pasada se implementó el Sistema Nacional de Evaluación, Acreditación y Certificación Institucional (SINEACE). Sin embargo, se sabe poco sobre la pertinencia de su diseño organizativo, las capacidades institucionales con que cuenta, su validez y legitimidad. Y menos aún de lo que ha hecho hasta hoy y lo que ha logrado.

Otro campo prioritario de análisis en la educación superior, sobre todo la universitaria, es el referido a la investigación; qué se hace en investigación 
en las universidades, cómo se aprenden las competencias investigativas, qué disposiciones institucionales hay para ello, con qué recursos se cuenta y cómo se los utiliza; qué rol desempeñan las universidades frente a las necesidades de conocimiento, evidencias y propuestas validadas para el desarrollo local; qué papel vienen cumpliendo en el desarrollo de las políticas de ciencia y tecnología.

Una tercera área de estudio es la del ajuste de la oferta de la educación técnica y ocupacional a las necesidades del mercado de trabajo. Qué se está haciendo para dar señales que faciliten el acercamiento entre los ofertantes de educación y la empresa, qué con respecto a la inserción laboral de los egresados, qué experiencias y prácticas tenemos en estos campos, qué resultados se ha alcanzado.

\section{Referencias}

Alcázar, L. (2008). Asistencia y deserción en escuelas secundarias rurales del Perú. En M. Benavides (Ed.). Análisis de programas, procesos y resultados educativos en el Perú: contribuciones empíricas para el debate. (pp. 41-82). Lima: GRADE.

Alcázar, L., \& Cieza, N. (2002). Hacia una mejor gestión de los centros educativos en el Perú. El caso de Fe y Alegría. (Documento inédito). Apoyo.

Alcázar, L., \& Valdivia, N. (2011). Descentralización y presupuesto de la educación pública en el Perú. Avances y desafíos. Revista Peruana de Investigación Educativa, 3, 7-51.

Ames, P. (2008). Construyendo equidad y democracia en la escuela: evaluación de dos modelos de intervención educativa en Lima y Cusco. En M. Benavides (Ed.). Análisis de programas, procesos y resultados educativos en el Perú: contribuciones empíricas para el debate. (pp. 365-402). Lima: GRADE.

Ames, P., \& Uccelli, F. (2008). Formando futuros maestros: observando las aulas de institutos superiores pedagógicos públicos. En M. Benavides (Ed.). Análisis de programas, procesos y resultados educativos en el Perú: contribuciones empíricas para el debate. (pp. 131-175). Lima: GRADE. 
Arteta, N. (2010). Respuestas de los docentes a las presiones institucionales de cambio: el caso de un programa de capacitación en una escuela pública de Villa el Salvador. En M. Benavides \& P. Neira (Eds.). Cambio y continuidad en la escuela peruana: una mirada institucional a la implementación de programas, procesos y proyectos educativos. (pp. 119-160). Lima: GRADE.

Balarín, M., \& Cueto, S. (2008). La calidad de la participación de los padres de familia y el rendimiento estudiantil en las escuelas públicas peruanas. Lima: Niños del Milenio / GRADE.

Barrantes, R., \& Iguíñiz, J. (2004). Educación. En CIES (Ed.). La investigación económica y social en el Perú, 1999 - 2003. (pp. 155-187). Lima: CIES.

Bello, M., \& Villarán, V. (2009). Las relaciones de la escuela con la familia y la comunidad. En el camino hacia la equidad. En N. López (Ed.). De relaciones, actores y territorios. Hacia nuevas políticas para la educación en América Latina. (pp. 115-170). Buenos Aires: IIPEUNESCO.

Beltrán, A., \& Seinfeld, J. (2011). Hacia una educación de calidad: la importancia de los recursos pedagógicos en el rendimiento escolar. Lima: Universidad del Pacífico/CIES.

Benavides, M. (2007). Lejos (aún) de la equidad: la persistencia de las desigualdades educativas en el Perú. En GRADE (Ed.). Investigación, politicas y desarrollo en el Perú. (pp.457-483). Lima: GRADE.

Benavides, M., Rodrich, H., \& Mena, M. (2009) Niveles de acoplamiento y desacoplamiento en la relación familia-escuela en contextos rurales: el caso de una muestra de familias de Quispicanchis-Cusco. Revista Peruana de Investigación Educativa, 1, 7-30.

Benavides, M., \& Rodríguez, J. (2006a) Políticas de educación básica 20062011. Lima: CIES/GRADE.

Benavides, M., \& Rodríguez, J. (2006b) Investigación y política educativa en el Perú. Lecciones de los estudios promovidos por el CIES. Lima: CIES.

Botto, M. (2011). Think Tanks en América Latina: radiografía comparada de un nuevo actor político. En N. Correa \& E. Mendizábal (Eds.). Vínculos entre conocimiento y política: el rol de la investigación en el debate público en América Latina. (pp. 83-111). Lima: CIES. 
Calónico, S., \& Ñopo, H. (2007). Retornos a la educación privada en el Perú. Washington: Banco Interamericano de Desarrollo.

Carrasco, G. (2007).Calidad y equidad en las escuelas peruanas: un estudio del efecto escuela en la prueba de matemática PISA 2000. Lima: CIES/DESCO.

Consejo Nacional de Educación. (2010). Balance y propuestas para avanzar en la descentralización educativa. Lima: Consejo Nacional de Educación.

Cuenca, R., \& Stojnic, L. (2008). Perú: carrera pública magisterial y el discurso del desarrollo profesional. Buenos Aires: FLAPE.

Cuenca, R. (2011). Discursos y nociones sobre el desempeño docente. Diálogos con maestros. En Consejo Nacional de Educación (ed.). Hacia una propuesta de criterios de buen desempeño docente. Estudios que aportan a la reflexión, al diálogo y a la construcción concertada de una política educativa. (pp. 11-70). Lima: CNE.

Cuenca, R. (2008). Educación. En CIES (Ed.). La investigación económica y social en el Perú, 2004 - 2007. pp. (127-170). Lima: CIES.

Cueto, S. (2007). Las evaluaciones nacionales e internacionales de rendimiento escolar en el Perú: balance y perspectivas. En GRADE (Ed.). Investigación, políticas y desarrollo en el Perú. (pp. 404455). Lima: GRADE.

Cueto, S., Guerrero, G., León, J., Zevallos, A., \& Sugimaru, C. (2010) De quinto de primaria al fin de la secundaria en seis años: un estudio longitudinal en Puno. Lima: GRADE/CIES.

Cueto, S., Torero, M., León, J., \& Deustua, J. (2008). Asistencia docente y rendimiento escolar: el caso del programa META. Lima: GRADE.

Cuglievan, G., \& Rojas, V. (2008). La gestión escolar en el marco de la autonomía: una mirada desde el cotidiano a cinco instituciones educativas estatales de Lima. En M. Benavides (Ed.). Análisis de programas, procesos y resultados educativos en el Perú: contribuciones empíricas para el debate. (pp. 297-342). Lima: GRADE.

Eguren, M., González, N., \& de Belaunde, C. (2008). ¿Lección para el maestro? Logros y limitaciones de los programas de capacitación docente en el Perú. Lima: Instituto de Estudios Peruanos. 
Escobal, J., Saavedra, J., \& Suárez, P. (2003). Shocks económicos y cambios en los patrones de escolaridad y gasto educativo. Lima: Niños del Milenio/GRADE.

Escobal, J., \& Ponce, C. (2006). La liberalización del comercio y el bienestar de la infancia: evaluando el impacto del acuerdo de Libre Comercio entre Perú y Estados Unidos. Reino Unido: Niños del Milenio.

Garfias, M. (2009) La investigación en la universidad pública regional y los fondos del canon 2004-2008. Lima: IEP/CIES.

Gonzales, N., de Belaunde, C, \& Eguren, M. (2008) El Estado y la burocracia de los organismos intermedios del sector educación: un acercamiento a los funcionarios. Informe de investigación. (Inédito).

Guerrero, G. (2010) Del dicho al hecho hay mucho trecho: una análisis de la implementación de la Política Nacional de Educación Bilingüe Intercultural en Puno, Perú. En M. Benavides \& P. Neira (Ed). Cambio y continuidad en la escuela peruana: una mirada institucional a la implementación de programas, procesos y proyectos educativos. (pp. 55-118). Lima: GRADE.

Guerrero, L. (2009). La educación en los tiempos del APRA: balance 20062009. En R. Cuenca (Ed.). Política docente: balance del periodo. (pp.1536). Lima: Foro educativo.

Laura, C., \& Bolívar, E. (2009). Una Laptop por niño en escuelas rurales del Perú: un análisis de las barreras y facilitadores. Lima: Universidad Nacional de San Agustín / CIES.

Miranda, L. (2008). Factores asociados al rendimiento escolar y sus implicancias para la política educativa en el Perú. En M. Benavides (Ed.). Análisis de programas, procesos y resultados educativos en el Perú: contribuciones empíricas para el debate. (pp.11-40). Lima: GRADE.

Montero, C. (2011). Estudio sobre acompañamiento pedagógico. Experiencias, orientaciones y temas pendientes. En Consejo Nacional de Educación (Ed.). Hacia una propuesta de criterios de buen desempeño docente. Estudios que aportan a la reflexión, al diálogo y a la construcción concertada de una política educativa. (pp. 71-172). Lima: CNE. 
Montero, C. (2008). Capacitación y equidad educativa: análisis de la estrategia, cobertura y distribución de los programas de formación en servicio. (Documento inédito).

Montes, A. (2010). La descentralización educativa y sus efectos en la mejora de las condiciones educativas: el caso de las instituciones públicas de nivel secundario en la ciudad de Arequipa. Economía y Sociedad, 76, 24-30.

Muñoz, F. (2009). Los caminos cruzados de la participación ciudadana en educación: entre el mejoramiento de la calidad de la educación y la construcción de ciudadanía. Un estudio colectivo de casos en Piura. Revista Peruana de Investigación Educativa, 1, 31-60.

Neira, P., \& Benavides, M. (2010). La escuela frente al cambio: el caso de un programa de intervención educativa en la sierra norte del Perú. En M. Benavides \& P. Neira (Eds.). Cambio y continuidad en la escuela peruana: una mirada institucional a la implementación de programas, procesos y proyectos educativos. (pp. 161-198). Lima: GRADE.

Pariguana, M. (2011). Trabajo adolescente y deserción escolar en el Perú. Lima: CIES / GRADE.

Oliart, P. (1996). ¿Amigos de los niños? Cultura académica en la formación del docente de primaria. Lima: GRADE.

Rodríguez, J. (2007). La política educativa durante el primer año del gobierno aprista. Lima: CIES.

Rodríguez, J., \& Garro, M. (2011) Implicancias de las evaluaciones nacionales del rendimiento educativo. En DESCO (Ed.). El quinquenio perdido. Crecimiento con exclusión. Colección Perú Hoy. (pp. 125-146). Lima: DESCO.

Santiago, A., Severin, E., Cristia, J., Ibarrarán, P., Thompson., J \& Cueto, S. (2010) Evaluación experimental del programa "una laptop por niño" en Perú. Aportes BID, 5, 1-12.

Stojnic, L., \& Sanz, P. (2007). Democratizando la gestión educativa regional. Dilemas y posibilidades de los Consejos Participativos Regionales en Educación (COPARE). Lima: Proeduca-GTZ.

Turpo, O. (2011). Concepciones y prácticas evaluativas de los docentes del área curricular de CTA de las II.EE. pública de educación secundaria de Arequipa (Perú). Revista Peruana de Investigación Educativa, 3, 159-200. 
Uccelli, F. (2008). Los programas no escolarizados de educación inicial: ¿debilidad, negligencia o incapacidad estatal? (Inédito).

Valderrama, J., \& Salgado, V. (2010). ¿Qué caracteristicas definen a un buen profesor? El caso del sexto grado en las escuelas peruanas. Lima: CIES/ Universidad Nacional de Ingeniería.

Valdivia, N., \& Díaz, H. (2008). Diagnóstico de los organismos intermedios del sistema educativo peruano: un estudio de casos de las Unidades de Gestión Educativa Local-UGEL. En M. Benavides (Ed.). Análisis de programas, procesos y resultados educativos en el Perú: contribuciones empíricas para el debate. (pp. 275-296). Lima: GRADE.

Vargas, P., \& Zevallos, A. (2009). Evaluando el impacto de shock negativos en la deserción. Identificando efectos heterogéneos mediante metodologías no paramétricas para el caso peruano. Lima: GRADE/CIES.

Yamada, G. (2006). Retornos a la educación superior en el mercado laboral: ¿vale la pena el esfuerzo? Lima: Universidad del Pacífico/CIES.

Zelaya, L. (2011). Percepciones de los agentes educativos sobre la formación para docentes de Educación Inicial que brinda un Instituto Pedagógico Público. Tesis de Maestría en Educación. Universidad Peruana Cayetano Heredia.

Zevallos, R. (2010). ¿La misma historia? El currículo de historia en dos colegios de la élite limeña". En M. Benavides \& P. Neira (Eds.). Cambio y continuidad en la escuela peruana: una mirada institucional a la implementación de programas, procesos y proyectos educativos. (pp.1754). Lima: GRADE. 